\title{
JOVENS QUE TENTAM SUICÍDIO E NARCISISMO DESTRUTIVO: DOIS MODELOS COMPREENSIVOS DO FENÔMENO SUICIDA ${ }^{1}$
}

\author{
YOUNGSTERS THAT ATTEMPT SUICIDE AND DESTRUCTIVE NARCISSISM: \\ TWO COMPREHENSIVE MODELS OF THE SUICIDE BEHAVIOR
}

Roosevelt M.S. Cassorla

Docente.Departamento de Psicologia Médica e Psiquiatria. Faculdade de Ciências Médicas - UNICAMP; Psicanalista-International Psychoanalysis Association.

CoRRESPONDÊNCIA: Rua Joaquim Novais, 79/61. CEP:13015-140 Campinas-SP. E-mail: rcassorla@sbpsp.org.br

Cassorla RMS. Jovens que tentam suicídio e narcisismo destrutivo: dois modelos compreensivos do fenômeno suicida. Medicina (Ribeirão Preto) 2005; 38 (1): 45-48

RESUMO: Modelo do Estudo: O trabalho visa apresentar resultados de investigações anteriores do autor referentes a modelos compreensivos para o comportamento suicida. Comentários: No primeiro modelo discute-se a "história natural de jovens que tentam suicídio", que implica num mundo interno sentido como esvaziado, estimulando a busca de relações simbióticas, que quando ameaçam desfazer-se levam a risco de desestruturação e fantasias de busca da plenitude com a morte. No segundo, "narcisismo destrutivo" mostra-se como autoexigências cruéis, quando não satisfeitas, levam a sensação de fracasso e loucura, o ato suicida parecendo ser uma saída. Finalmente discutem-se esses modelos em relação ao maior risco suicida em médicos e estudantes de medicina.

Descritores: Suicídio. Jovens. Narcisismo Destrutivo. Médicos. Estudantes de Medicina.

O objetivo deste trabalho é apresentar, suscintamente, resultados de trabalhos anteriores ${ }^{1 / 4}$ visando discuti-los na Jornada do LAMS, como exemplos de modelos compreensivos referentes a comportamentos suicidas. Espera-se, em particular, que o debate possa desenvolver a capacidade de observação, inclusive de auto-observação, dos colegas médicos e estudantes de medicina. Lembremos que na área médica o risco suicida é maior que na população geral.

Dentre as inúmeras formas como podem se apresentar os fenômenos e mecanismos suicidas, me deterei em duas, possivelmente as mais comuns em pronto-socorros, na prática do médico clínico e do profissional de saúde mental. Talvez elas possam constituir-se em modelos tentativos que nos inspirem na busca de outras compreensões e também em outras condutas. Esses modelos são expressos com a partir de conceitos psicanalíticos, que tentei reduzir ao máximo e que serão explicitados durante o debate, quando necessário.

\section{1- JOVENS QUE TENTAM SUICÍDIO}

No primeiro modelo o médico, psicoterapeuta ou psicanalista, recebe geralmente, uma jovem que tentou suicídio e que chega com o rótulo de histérica. A disciplina do profissional de saúde o obriga a eliminar rótulos, preconceitos, supostos saberes e teorias, para observar o paciente, como ele se apresenta. Após as consultas iniciais, caso se permita à jovem formar um vínculo com o profissional, este percebe que a paciente se entrega ao tratamento, quase que se gruda ao terapeuta, criando uma espécie de dependência ameaçadora para o profissional. Logo se percebe que

${ }^{1}$ Texto discutido na Jornada do LAMS- Faculdade de Medicina de Ribeirão Preto - agosto 2004. 
a qualidade desse vínculo encobre ameaças terríveis de desestruturação, de estilhaçamento, de liquefação do ser, na falta de palavras que pontuem o indizível. O "grude", a simbiose, melhor ainda o parasitismo, encobrem e tentam colar, unir, esse ser ameaçado. Quando se consegue verbalizar o terror, ele pode ser comparado ao desespero de perder-se no espaço infinito. Caso estejamos trabalhando em forma psicanalítica, entraremos em contato com as peculiariedades da dinâmica do mundo interno, individual, nunca similar de paciente para paciente. Mas, a somatória de observações e o trabalho interdisciplinar, em que solicitamos a ajuda de outras áreas do conhecimento, nos permite descrever a "história natural da tentativa de suicídio" nessas jovens, diferente para cada uma, mas com elementos comuns, na maioria.

No relato e na realidade de quase todas as paciente se encontram indícios de que essas jovens foram bebezinhas não desejadas, sentidas como uma carga e havia outros seres filicidas no ambiente, objetivamente. A figura paterna comumente era ausente. No entanto, algo permitiu que essas crianças não psicotizassem manifestamente. Graças ao trabalho psicanalítico, pela reconstrução hipotética, supus que o processo de individuação processou-se de forma problemática, as crianças procurando uma fusão simbiotizada, mas que não era possível. Poderíamos supor que a relação primitiva continente-contido, a relação mãe-bebê (onde "mãe" é mais do que a mãe biológica) teria fracassado, com tentativas de parasitismo, essas configurações sendo mais comuns que momentos de relação simbiótica adequada. Dessa forma o bebê sentir-se-ia aterrorizado, procurando agarrar-se a um continente rejeitante.

$\mathrm{Na}$ adolescência isso é revivido, a moça procurando desesperadamente um objeto (ser humano) suposto continente. Esse objeto, geralmente o namorado, costuma permanecer idealizado (como proteção contra as ansiedades persecutórias), mas, em última instância, assume as mesmas características frágeis e não confiáveis do mundo interno. "Se este rapaz me aceita, a mim, tão sem valor, é porque ele tem menos valor ainda". Essa é a fantasia predominante e nesse jogo de cisões e identificações a jovem se vê enredada, potencializando sua baixa auto-estima e ameaça de desestruturação.

Por outro lado o parceiro, objeto que tem que ser controlado, tende a ser exogâmico, mas as fantasias edípicas mal elaboradas (já que o desprendimento inadequado impediu a relação triangular satisfatória) complicam o processo. Fenomenologicamente observamos uma fusão sujeito-objeto, repetida na relação com o terapeuta (transferência). E, nela serão revividas desde a dessimbiotização ou desprendimento inadequados, até as fantasias edípicas, mal elaboradas. Será, portanto, uma relação narcísica, de fusão indiscriminada, em que o objeto oscila rapidamente de idealizado a persecutório, mas sempre de uma forma confusional.

Quando existe uma ameaça ou um perigo de perder-se o objeto com o qual está confundida, a adolescente se sente aterrorizada. Todos seus objetos foram projetados identificativamente no depositário, e ali mantidos, idealizados. Ele serão reintrojetados, violentamente, mas agora como frustrantes, persecutórios, carregados de maldade. Devido às cisões e confusões entre bom e mau objeto, concomitantemente, a jovem se sente esvaziada, tendo perdido seus objetos bondosos, que também foram expelidos, ficando perseguida também pela fantasia de que eles se foram e são irrecuperáveis.

A idéia suicida e a tentativa ocorrem como uma forma desesperada de voltar a um estado de fusão idealizada primitiva. Ao mesmo tempo, como vimos acima, os conteúdos confusos e persecutórios que a assolam, serão expelidos, em particular para dentro do namorado e da família. Aqui aparece o componente agressivo do ato suicida. Dessa forma, a jovem se livra, novamente, dos objetos maus. Desta vez, para sempre, ao mesmo tempo que, em sua fantasia, reencontra o objeto idealizado, intra-uterino, nirvânico, na morte. Desta vez não falhará, pois da morte (ou desse mundo sem necessidades) não se volta, ainda que isto seja vivenciado de forma confusa.

Outras maneiras que estas jovens encontram para retomar as fantasias de fusão são o uso de drogas, a gravidez (identificando-se com o bebê), a adição a seitas religiosas e a grupos com ideologias fanáticas. As fantasias são similares às descritas acima, mas sem o risco objetivo da não reversão, como na morte. Mais raramente as jovens se defendem da dependência fusional, criando uma carapaça protetora que as torna, aparentemente, auto-suficientes e independentes. Mas, essa defesa pode desabar a qualquer momento.

Verifica-se também que as mães destas crianças haviam passado por vicissitudes similares em sua infância e adolescência e pôde-se supor que os seus bebês tenham sido utilizados como depositários de suas ansiedades e fantasias, identificando-se com elas. A relação continente-contido seria, possivelmente, parasitária, agora do lado da mãe.

A preponderância de jovens do sexo feminino não implica que o mesmo processo não ocorra no sexo masculino. Mais recentemente, tenho observado estes mesmos mecanismos em rapazes. A diferença com 
as moças é que, quando ocorre a ameaça de perda do objeto fusionado, os rapazes tendem a reagir heteroagressivamente; as moças, como vimos, se atacam a si mesmas. É possível que aqui encontremos pistas para alguns tipos de violência doméstica e para muitos dos chamados crimes "passionais". Isto não quer dizer que rapazes, com essas características, não tentem suicídio, e que moças não reajam preponderantemente de forma hetero-agressiva. Penso que ainda existem mais dúvidas que certezas, em relação ao comportamento diferencial entre os sexos.

Para alguns autores, os pacientes descritos correspondem aos chamados "borderlines". A despeito de concordar com sua semelhança, me parece que são pacientes menos indiscriminados, mais integrados, não correspondendo aos quadros típicos "borderline". Quando surgem os aspectos psicóticos, com cisões, indiscriminações e confusões, elas são mais limitadas que nos "borderlines" típicos, persistindo uma parte integrada razoável. E é por isso que os componentes triangulares podem também emergir.

\section{2- UM SEGUNDO MODELO: NARCISISMO DESTRUTIVO}

Quanto aos melancólicos e psicóticos, infelizmente, estes nem sempre são encaminhados pelos psiquiatras para psicoterapias. Ao mesmo tempo, são esses pacientes os que se matam antes de procurar ajuda, ou quando ela é lenta ou não adequada. Muitos se assemelham ao que se segue.

Sérgio*, com 45 anos, apresentou-se à entrevista, fenomenologicamente, como um melancólico, ainda que procurando mascarar-se. Tentou matar-se num quarto de hotel, com uma "overdose" de psicotrópicos, e sobreviveu porque foi descoberto por mero acaso. Não queria um psiquiatra, estando certo que somente a psicanálise resolveria seu problema. Tentava seduzir-me, num momento maníaco, logo após a tentativa, para que eu o aceitasse para análise, estimulando-me a efetuar um conluio perverso, e assim certamente ele acabaria se matando. Não me foi difícil perceber isso e consegui convencê-lo a procurar um colega psiquiatra, onde já chegou como melancólico típico, com fortes idéias suicidas, tendo sido internado.

Saído do hospital, chegou-me como um paciente deprimido, mas principalmente com uma estrutura narcísica, um executivo, que antes vivia na onipotência, mas a havia perdido ao ter fracassado em seus negócios arriscados. Aspectos superegóicos sádicos decorriam da identificação arcaica com objetos mortos-vivos, que o perseguiam exigindo-lhe atingir a perfeição total, para repará-los maniacamente. Uma vez que não a conseguira, obedecia às ordens desses objetos, punindo-se e ao mesmo tempo buscando outra perfeição, sem necessidades, na morte. Na relação transferencial me atacava, exigindo que eu encenasse seus objetos sádicos, que eu lhe exigisse uma perfeição absoluta, ao mesmo tempo que me acusava por isso. Fugia de qualquer ansiedade depressiva através de atos, como o uso de bebidas, drogas e velocidade, com o que tentava maniacamente sentir-se onipotente, ao mesmo tempo que buscava a morte.

Concomitantemente tentava fazer-me viver seus terrores e culpas, mas tinha também a esperança que eu não sucumbisse a suas ansiedades projetadas. $\mathrm{O}$ trabalho de dissecção dessas fantasias, permitiu que introjetasse alguns aspectos de objeto continente, suficientes para recomeçar sua vida, com alguma humildade e discriminação. Conseguiu trabalho, e saiu-se relativamente bem, ainda que seus objetos sádicos continuassem ativos. Com o tempo pôde diminuir a intensidade de suas identificações projetivas, dentro do analista, cuja função primordial era negar sua dependência, não tomar contato com a inveja do profissional, e tentar manter-se num mundo narcísico. No entanto, frente a algum desenvolvimento mais evidente, os componentes destrutivos e invejosos re-apareciam.

O caso relatado, de Sérgio, teorizado (lembro que teorias não são fatos nem fenômenos) nos leva a pensar em estruturas (palavra bastante ruim, porque não há "estruturas" que dêem conta da mente humana), estruturas narcísicas, em que em vez da pulsão de vida, é a de morte que atinge o indivíduo. No chamado narcisismo destrutivo ocorreria uma fusão patológica das pulsões de vida e de morte, e a teoria da inveja nos explica a confusão. A impossibilidade de sentir-se dependente do analista, como antes não aceitou ser dos pais, numa revivescência, faz com que o paciente prefira não ser, morrer, negar o fato de seu nascimento, e também destruir seu progresso e insight analíticos, representantes da criança dentro dele, que ele sente que o analista, enquanto representante dos pais, gerou. Agora o paciente quer desistir da análise, ou mais frequentemente atua de maneira autodestrutiva, destruindo seu sucesso profissional e suas relações pessoais. O suicidio, o desaparecer no esquecimento, se expressa muito abertamente, sendo a morte idealizada como uma solução

Trata-se de um compósito de material clínico, visando não identificação e manutenção de sigilo ético. 
para todos os problemas. Estaríamos aqui praticamente com a pulsão de morte quase em estado puro. A teorização apresentada se aproxima do que os autores modernos têm chamado "organizações patológicas, em que aspectos destrutivos, sedutores e enganadores funcionam como uma máfia interna, prometendo proteção mafiosa se o indivíduo se sujeitar a conluios perversos. Nada muito diferente do que ocorre em nossa sociedade narcísica atual, com seus aspectos corruptos, mafiosos e mentirosos. Mas, este é outro assunto...

Entre médicos e estudantes de medicina não raro os comportamentos suicidas têm características que se assemelham aos dois modelos descritos. Trata-se de pessoas exigentes consigo mesmas, comu-mente com sucesso escolar, profissional ou científico. No entanto, têm dificuldades em lidar com as frustrações do mundo real, e quando se defrontam com elas inclinam-se a tomá-las como fracasso pessoal. Sua vida afetiva é pobre, difícil e desvalorizada frente à área intelectual. Em algum momento, quando as pessoas se defrontam com um vazio intenso, estimulado por supostos "fracassos" dependentes de auto-exigências sádicas, e sem apóio afetivo, o terror inconsciente de "não existência" os faz pensar em morrer. A idéia suicida se articula com fantasias inconscientes de busca de outra vida sem necessidades, de agressão ao ambiente frustrante, auto-punição pelo fracasso, e/ou outras fantasias altamente sofisticadas que dependerão da constituição peculiar de seus mundos internos. A sociedade, por outro lado, estimula a competição e o orgulho profissional, que pode tornar-se arrogância. Quando esta desaba o médico se defronta com um vazio, uma vida sem objetivos, uma sensação de fracasso e um questionamento sobre o viver. Isso pode ser acompanhado de doenças físicas, somatizações, tristeza, atuações sociais (abandono da Faculdade, de profissão, separações conjugais, etc.), depressão (que chamamos "narcísica"), uso de substâncias psicoativas, e, como vimos, idéias suicidas. $\mathrm{O}$ risco de acidentes (suicídios inconsciente) aumenta. A facilidade em obter produtos mortíferos por parte de médicos, e o conhecimento pormenorizado de sua ação, implica em maiores riscos de vida. Relações simbióticas podem coexistir com a dinâmica apresentada, ao lado do isolamento afetivo, oscilando entra os dois extremos.

É necessário que a classe médica e os estudantes de medicina questionem sua qualidade de vida, e a forma como convivem numa sociedade narcísica, estimulante da competição e do sucesso perversos, inibindo a afetividade. No entanto, verificamos que comumenta personalidades como as descritas, procuram a Medicina, justamente porque a seleção (vestibulares, por exemplo), facilita o ingresso de pessoas com esses tipos de conflito na profissão. A Escola Médica pode ser o lugar privilegiado para que ocorra prevenção, diagnóstico precoce e tratamento adequado, possibilitando que os excessos sejam dirigidos de forma produtiva, para a vida e não para a morte.

Cassorla RMS. Youngsters that attempt suicide and destructive narcissism: two comprehensive models of the suicide behavior. Medicina (Ribeirão Preto) 2005; 38(1): 45-48.

ABSTRACT: Model of the study: The paper presents the results of the author's previous investigations referred to comprehensive models of suicidal behavior. Comments: The first model shows the "natural history of the suicide attempt in youngsters". In this model is identified an empty internal world that stimulate the search of symbiotic relationships. When these relationships threat to finish appear the risk of breakdown. Then emerge phantasies of search prime in death. In the second, "destructive narcissism" its explained how cruel self demands, when not satisfied, takes to the feeling of fail or insanity. The suicidal act seems to be a solution. Finally these models are discussed bringing into relation with the higher suicide risk of physicians and medicine students.

Keywords: Suicide. Youngsters. Destructive Narcissim. Physicians. Medicine Students.

\section{REFERÊNCIAS BIBLIOGRÁFICAS}

1 - CASSORLA RMS. Depression and suicide in adolescence. In: The health of adolescents and youths in the Americas. Washington ,DC.:Word Health Organization, Pan American Health Association; 1985. p.156-69. (Scientific Publication, 489).
2 - CASSORLA RMS. Do suicídio: estudos brasileiros. 2a.ed. Campinas:Papirus; 1998.

3 - CASSORLA RMS. Suicídio e autodestruição humana. In: Werlang BG, Botega NJ. Comportamento suicida. Porto Alegre: Artmed; 2004. p.21-33.

4 - CASSORLA RMS. 0 que é suicídio. 5a. ed. São Paulo:Ed. Brasiliense; 2004. (No prelo). 